\title{
Sustainable innovation through management systems integration
}

\begin{abstract}
In an increasingly competitive world driven by fast changes, companies are challenged to pursue sustainable development through innovation. This matter has led to the discussion about how organizations manage innovate in a way that they meet the demands of sustainability. Recently, researchers have identified the integration of management systems (IMS) as a potential practice to support both innovation and sustainability. This research aims to contribute to this field by exploring the relationship between IMS and sustainable innovation. Although substantial research has analyzed sustainable innovations in developed countries, there is still scarce empirical evidence including also less developed countries. This exploratory research addresses this current limitation by including European and Latin-American companies. Results suggest that IMS provides the managerial support to foster the adoption of cleaner production technologies. The latter is of particular relevance towards the development of sustainable products that deal with the technical, environmental and social impacts of new products. However, the role of IMS towards sustainable product innovation is not significant. Moreover, no significant differences are found in the development of sustainable innovations among candle manufacturers in Europe and Latin-America. Bigger companies are found more innovative in terms of the adoption of cleaner production technologies, but no significant differences are observed in terms of sustainable product innovation. Besides these findings, this study also contributes to the state-of-the-art by proposing a proxy measure of IMS not restricted to certified organizations. All in all, this is one of the first articles to relate IMS, the adoption of cleaner production technologies and sustainable product innovation studying a sample of companies allocated in countries of diverse economic backgrounds.
\end{abstract}

Keywords: Management systems integration; innovation; sustainability; cleaner production.

Paper type: Research paper 


\section{Introduction}

The global concern about environmental care, social awareness and sustainability has increasingly caught the attention of practitioners and researchers (Gianni et al., 2017; Oskarsson and Malmborg, 2005). In light of the current business situation, sustainable development emerged as a new competitive advantage, including sustainable initiatives and a wider perspective of profitability, that involves environmental and social values (Sroufe, 2017). The inclusion of these parameters within the strategic management of organizations poses the basis for sustainability (Elkington, 1997). To this end, companies are required to innovate, change their organizational structure and integrate their strategies to overcome barriers and become more sustainability-oriented (Kennedy et al., 2017; Lozano et al., 2016).

To meet the challenge of innovating effectively and maximizing the value of sustainability demands, it is necessary to have well-structured management systems (MSs) (Wagner, 2007). According to the International Organization for Standardization (ISO) MSs are 'the way in which an organization manages the inter-related parts of its business in order to achieve its objectives' (ISO, 2018). Depending on the specific objectives, MSs are classified as quality (QMS), environmental (EMS), occupational health and safety (OHSMS), corporate social responsibility (CSR), among others (Jørgensen et al., 2006). Towards sustainability, their most relevant limitation lays on the fact that the sole implementation of an isolated MS cannot cover all the sustainability dimensions (Darnall et al., 2008) since MSs are too narrow and focus only on specific kinds of issues (Esquer-Peralta et al., 2008). For this reason, organizations that aim to implement sustainability best practices might require adopting more than one MS, harness their synergies and integrate them (Mustapha et al., 2017).

The integration of management systems (IMS) allows organizations to be simultaneously coherent and consistent in satisfying the demands of sustainability in an optimal way (Rebelo et al., 2016; Salomone, 2008). This argument has led IMS to be acknowledged as a relevant sustainable management approach (Gianni et al., 2017; Jørgensen, 2008; Mustapha et al., 2017; Rebelo et al., 2016; Siva et al., 2016). As such, IMS has been positively related to innovations in general based on theoretical frameworks (Bernardo, 2014) and empirical statistical evidence (Hernandez-Vivanco et al., 2016; Simon and Petnji Yaya, 2012). However, how IMS is related to sustainable innovation (rather that innovation in general) remains a major research gap (del Río et al., 2016; Nunhes et al., 2016; Ramos et al., 2018), which will be explored in this article.

Companies in pursue of sustainability reflect this approach through the improvement and creation of new processes and products (Boons et al., 2013). The Cleaner Production (CP) framework has 
been recognized as a remarkable voluntary corporate initiative towards sustainability (Bonilla et al., 2010; Lozano, 2012). This strategy seeks to continuously applicate integrated preventive actions to increase companies' efficiency and reduce at the source any environmental and social risks (UNEP DTIE, 1996). To this end, companies utilize technological solutions to minimize the environmental and social impacts of their operations before they leave a production process (Kemp and Volpi, 2008; UNEP DTIE, 1996; Vieira and Amaral, 2016). This objective is in line with sustainable product innovations, which seek to reduce, from the design, the environmental and social impacts over their entire life cycle (Rebelo et al., 2016; UNEP DTIE, 1996). Despite the substantial literature devoted to study sustainable process and product innovations, the empirical evidence in middle-income and developing countries is still under-researched (del Río et al., 2016). Therefore, this study will explore the relationship between the adoption of CP technologies and sustainable product innovation through a sample of companies based in countries with diverse economic backgrounds.

To sum up, the aim of this article is to contribute to the state-of-the-art by exploring whether IMS acts as a driver of sustainable innovation, within the framework of cleaner production. This research will explore these relationships based on empirical evidence of a specific industry in countries with different levels of economic development.

\section{Theoretical framework}

In this section, firstly sustainable innovation is analyzed in the context of CP to relate the adoption of CP technologies and sustainable product innovation. Then, the relationship between IMS and the adoption of CP technologies, and sustainable product innovation are analyzed.

\subsection{Sustainable process and product innovations}

According to the OECD (2005), both process and product innovations have different objectives; the former is related to the implementation of a new or significantly improved production or delivery methods. The latter is related to significant changes in the capabilities of goods or services. To become sustainably oriented, such innovations must benefit the TBL with measurable improvements (Sroufe, 2017). Thus, companies are challenged to manage the existing trade-offs between the economic, environmental and social impacts so that process and product innovations do not have (negative) consequences between them or in another area (Rocha et al., 2007). To this end, companies should implement radical innovations embedded in the companies' wider socioeconomic context (Boons et al., 2013).

From the operations standpoint, Muñoz-Villamizar et al. (2018) suggested that, in order to assess and improve their sustainable performance, companies should consider four factors: i) complying 
with their location's regulations and certifications, ii) rationalizing their resources across the value chain, iii) improving their raw materials through the implementation of circular economy strategies, and iv) improving their production processes. According to the authors, the latter is often the factor that has the greatest environmental impact since this is what companies can best manage directly. As a consequence, companies aiming to become sustainability-oriented seem to prefer beginning their transition from process innovations and then move forward to the other factors. In this line, Sroufe (2017) discussed that process improvements that enable energy conservation as well as waste reductions at source are necessary to bring new sustainable products to the market. According to the author, such new products would be designed using ecological and less hazardous new materials.

Given the strategic importance of adopting a sustainable management approach, Boons et al. (2013) identified that companies should be forthcoming to make great efforts to successfully achieve the required transitions. This means that, the more innovations related to the technical and sustainability attributes of new products, the larger the effort that companies must make. Thus, as long as creating sustainable products is profitable and customer oriented, companies ought to invest in such innovations and in actions to preserve the environment (Ramos et al., 2018). Such approach would foster, from the design, waste and emissions reductions, as well as the minimization of risks to the environment and society, in accordance with CP (Kemp and Volpi, 2008; UNEP DTIE, 1996; Vieira and Amaral, 2016).

Adopting a new technology, in particular if it is CP oriented, requires a great effort and a strong strategical commitment since it might implicate changing radically the companies' operations (Boons et al., 2013). According to the CP framework, such changes would be related to both: process and product innovations. Thus, it can be expected that companies that adopt CP technologies in pursue of sustainability will also introduce sustainable product innovations aiming to benefit the TBL, as stated in H1:

H1: The adoption of cleaner production technologies is positively related to sustainable product innovation.

\subsection{The integration of managements systems and the adoption of cleaner production technologies}

Companies are continuously challenged to comply with the different requirements of the multiple stakeholders. To this end, they implement individual MSs -such as QMS, EMS, OHSMS and CSRaimed to respond to their specific demands. In the course of this process, companies are faced with 
a "puzzle” of MSs that should be integrated into a unique and more efficient integrated MS (Rebelo et al., 2016). For this purpose, companies must firstly give the same (high) importance to all the MSs (certified or not) within the organization (Bernardo et al., 2017; Gianni et al., 2017; Gianni and Gotzamani, 2015; Zeng et al., 2007). To analyze how IMS is related to the adoption of CP technologies, the contributions of each MS are analyzed as follows.

EMSs are adopted to deal with the environmental dimension of the companies' operations, with the advantage that it promotes the better use of resources, which usually leads to cost reductions (Lozano, 2012). To reach this benefit, companies have to necessarily change and improve their current operations, so they must modify or introduce new processes (Lim and Prakash, 2014). When such innovations occur in the framework of an EMS strategy, companies aim to eliminate any potential environmental risk at source, which promotes the adoption of CP technologies (Radonjič and Tominc, 2006).

Even if the environmental motivations seem to be clear for implementing CP technologies, companies are usually more conscious about the quality dimension of their operations (Ramos et al., 2018). Interestingly, and from the QMSs' perspective, pollution could be considered as a 'quality defect' that should be reduced or eliminated at the source instead of just being controlled (Khanna et al., 2009). Although this objective is in line with the CP approach, it also demands companies to step further. To effectively obtain process innovations oriented to improve quality, the latter should be considered beyond the limited scope of control and inspection. Its adoption should be widened to the strategic vision of continuous improvement (Hoang et al., 2006; Moreno-Luzon et al., 2013).

Besides fostering environmental care, CP technologies should also pursue the minimization of risks posed to society, including workforce (UNEP DTIE, 1996). Thus, OHSMSs have a relevant role. Since adopting a new technology usually implicates new or different workforce risks, OHSMSs are useful to provide companies of the necessary means to manage them (Bottani et al., 2009; Santos et al., 2013). Simultaneously, OHSMSs contribute to the reduction of wastes and the improvement of quality, which complements the contributions of the other MSs (Lo et al., 2014; Zwetsloot, 1995).

Moreover, CSR is in line with EMSs and OHSMSs' goals, but expanding its frontiers outside the organization, so it takes place under the aegis strategic management (Lozano, 2012). Thus, it is not surprising that CSR and EMS are being increasingly adopted and integrated due to both, internal motivations (higher effectiveness) and external demands calling for more information regarding environmental and social performance (Oskarsson and Malmborg, 2005). According to the latter study, the adoption of CSR and EMS could foster innovation if (and only if) companies act proactively rather than just responding to the legal demands or the demands in the standards. Otherwise, such MSs might hinder instead of promote innovation (Oskarsson and Malmborg, 
2005). Henceforth, companies dealing with such proactive approach regarding environmental and social practices are replacing other companies with more traditional strategies such as low-price oriented. Thus, it seems that CSR, besides being aligned to the CP framework, reinforces the other MSs providing the organization of a more holistic strategy that includes sustainability priorities (Longoni and Cagliano, 2015). As a result, the CSR adoption seems to act a strategical support to promote the adoption of CP technologies through its sustainability-oriented framework.

By giving a high importance to all MSs, IMS captures their synergies to promote process innovations (Bernardo, 2014; Hernandez-Vivanco et al., 2016; Simon and Petnji Yaya, 2012). Moreover, IMS provides a sound focus and clear insights towards sustainability goals (Mustapha et al., 2017); i.e., to use efficiently resources/costs (Zwetsloot, 1995) and minimize environmental and social impacts (Gianni et al., 2017) through innovation (Rebelo et al., 2016). Thus, IMS seems to give companies the necessary managerial support to adopt CP technologies (Mustapha et al., 2017; Ramos et al., 2018; Vieira and Amaral, 2016) as stated in H2:

H2: The integration of management systems is positively related to the adoption of cleaner production technologies.

\subsection{The integration of management systems and sustainable product innovation}

Mustapha et al. (2017) recognized IMS as a sustainable green MS that stimulates companies to move towards a sustainability approach through the optimization of costs and time. The authors attributed such IMS benefits to the abatement of redundancies and the simultaneous enhancement of productivity. According to the conclusions of that study, it seems that IMS is more related to sustainable process innovation rather than product innovation.

In spite of the direct relationships between IMS and process innovations, sustainability professionals are well aware of the imperative need of applying this strategy across the value chain and involving both processes and products (Rebelo et al., 2016; Sroufe, 2017). On this basis, sustainable innovation is required not only to meet with the internal (process) CP requirements, but also to attend the needs of the different stakeholders across the value chain (Muñoz-Villamizar et al., 2018). It is in this process that IMS becomes crucial by its purpose of attending equally the needs and goals of the diverse stakeholders across the value chain (Jørgensen, 2008). Thus, the relationship between IMS and (sustainable) product innovation is plausible (Bernardo, 2014; Tarí and Molina-Azorín, 2010), but it seems not to be direct. Thus, the path of the relationship between IMS and sustainable product innovation has to be further developed. 
Although IMS and innovation have been generally positively related (Bernardo, 2014; Gianni et al., 2017), most studies have focused on a general definition of 'innovation' rather than the specific types of innovation proposed by the OECD (2005). Simon and Petnji Yaya (2012) present one of the first studies attempting to disentangle the IMS effects on the different types of innovations, namely process, organizational and marketing innovations. According to the authors, the better use of systems resulting of IMS fosters all three types of innovation, which in turn, improve customer satisfaction. These effects might be instrinsically atribitued to new and improved products (innovation). Although this last argument was not empirically tested in Simon and Petnji Yaya (2012), the significant relationship between IMS and product innovation was later found in Hernandez-Vivanco et al. (2016). The authors conclude that IMS improves the odds of innovating in both processes and products, but they also observe that companies must be open to collaborate with external parties -including the stakeholders of the supply chain- so that both process and product innovations are positively related; otherwise, process innovations might hinder product innovations. Thus, it seems that a previous relationship between IMS and process innovations is required so that both contribute to create new or improved products. This indirect relationship could be suspected to maintain when focusing on sustainable innovations.

To create sustainable products and achieve excellence, organizations must be proactive regarding continuous improvement and should implement organizational and process innovations (Rebelo et al., 2016). In this line, IMS not only that is a relevant an organizational innovation that endorses organizational efficiency (Bernardo, 2014), but it also fosters the adoption of sustainable process innovations, namely CP technologies (Mustapha et al., 2017; Ramos et al., 2018; Vieira and Amaral, 2016). The latter, as previously discussed, promotes sustainable product innovations, which integrate the technical, environmental and social dimensions of the new products (Rebelo et al., 2016). As a result, it can be hypothesized that IMS is significantly related to sustainable product innovations, but its relationship is mediated by the adoption of CP technologies. Hence, hypothesis H3 is stated as follows:

H3: The adoption of cleaner production technologies mediates the positive relationship between the integration of management systems and sustainable product innovation.

To sum up, Figure 1 shows the studied relationships: 


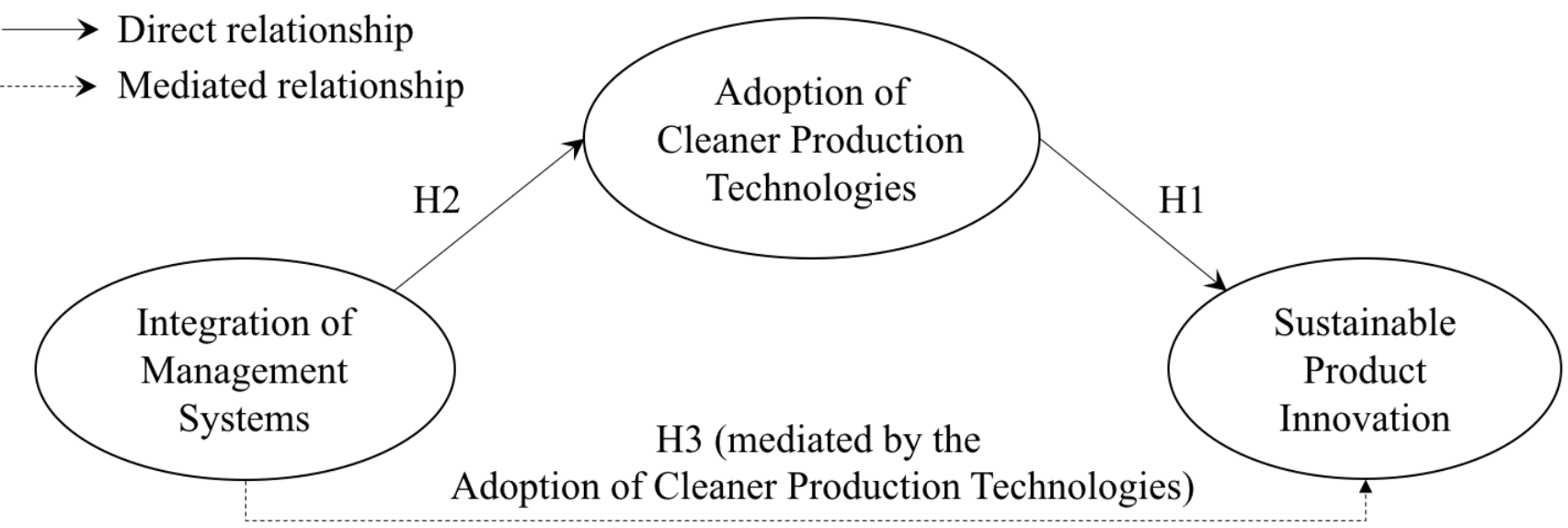

Figure 1. Model relating IMS and sustainable innovation

\section{Research methodology}

This section presents the methodological approach to test the hypotheses of this research. To this end, firstly the target population and sample selection is presented. Then, a statistical model is selected. Finally, the measurement of the selected variables is described.

\subsection{Population and sample selection}

The candle industry is of special interest to this study for three main reasons. Firstly, because from the ancient times candles have been involved in the debate of their potential indoor pollution and health effects (Faraday, 2001; Karataş and Gülder, 2012), which degree of danger depends on the process and raw materials used in their elaboration (Derudi et al., 2012; Manigrasso et al., 2017; Orecchio, 2011; Skovmand et al., 2017). Secondly, due to its traditional consumption among human history (Nordhaus, 1996), being nowadays widely used in the worldwide population. This allows studying countries in different stages of economic development. More specifically, it is estimated that half of Europeans use candles at least once a week (ComRes/AECM, 2015), while in the US, the annual retail sales are estimated at $\$ 2$ billion (Derudi et al., 2012). Finally, there are few official reports concerning the candle sector (Knight et al., 2001), and the scientific literature studying these issues from a managerial perspective is almost anecdotal.

To have a significant sample of the sector, this study surveyed the top-management of companies related to the most representative candle associations. Namely, the Latin American Candle Association (ALAFAVE), the European Candle Association (ECA), the Association of European Candle Makers (AECM) and the National Candle Association of the United States (NCA) allowed us to contact their members for this research. All contestants were part of the top-management, and their companies had a direct link with one of the abovementioned associations. The total number of 
candle manufacturers that met both requirements was 174: 61 linked to ALAFAVE, 22 to ECA, 64 to AECM and 27 to NCA. However, only European and Latin-American firms were willing to participate in this study.

The questionnaires were mainly based on the structure of the Community Innovation Survey (CIS, 2012) and the Spanish Innovation Panel (PITEC, 2007), both following the OECD (2005) guidelines. A version in English and in Spanish was prepared using Survey Monkey. It was firstly assessed by the candle associations' board. Then it was improved and pre-tested in five firms that validated it, so no further changes had to be done. The questionnaire is presented in the Appendix. It was sent via email in three rounds between October 2016 and February 2017, obtaining 40 valid answers: 20 Latin-Americans and 20 Europeans. The valid answers resulted in an overall response rate of $27.21 \%$ with a response error of $\pm 8.0 \%$ at $95 \%$ confidence. Table 1 summarizes the descriptive statistics of the sample. 
Table 1. Descriptive statistics of the sample.

\begin{tabular}{|c|c|c|c|c|c|c|c|c|c|c|c|c|c|}
\hline \multirow[b]{2}{*}{ Location } & \multirow[b]{2}{*}{$\mathbf{N}$} & \multicolumn{4}{|c|}{ Age in 2015} & \multicolumn{4}{|c|}{ Average Revenues during 2014/15a (thousand euros) } & \multicolumn{4}{|c|}{ Average Employees during 2014/15 } \\
\hline & & Mean & $\begin{array}{l}\text { Std. } \\
\text { Dev. }\end{array}$ & Min & Max & Mean & Std. Dev. & Min & Max & Mean & $\begin{array}{l}\text { Std. } \\
\text { Dev. }\end{array}$ & Min & Max \\
\hline $\begin{array}{l}\text { Latin- } \\
\text { America }\end{array}$ & 20 & 26.213 & 17.206 & 2 & 69 & 2,976.101 & $3,243.521$ & 55.711 & $10,884.920$ & 38.971 & 37.184 & 3.500 & 155 \\
\hline Argentina & 2 & 17.500 & 9.192 & 11 & 24 & 845.162 & 700.098 & 350.118 & $1,340.206$ & 14.500 & 1.414 & 13.500 & 15.500 \\
\hline Colombia & 5 & 23.200 & 13.312 & 2 & 36 & 3,348.206 & 3,363.646 & $1,017.133$ & $9,137.886$ & 65.936 & 28.333 & 20 & 98 \\
\hline Ecuador & 1 & 32 & (.) & (.) & (.) & $2,030.269$ & $()$. & (.) & (.) & 29 & (.) & (.) & (.) \\
\hline Guatemala & 1 & 4 & (.) & (.) & (.) & 2,728.548 & (.) & (.) & (.) & 34.541 & (.) & (.) & (.) \\
\hline Paraguay & 1 & 35 & (.) & (.) & (.) & 3,357.296 & $()$. & (.) & (.) & 42.500 & (.) & (.) & (.) \\
\hline Peru & 5 & 17 & 13.565 & 4 & 40 & 408.067 & 546.575 & 55.711 & $1,353.548$ & 14.315 & 8.071 & 3.500 & 26 \\
\hline $\begin{array}{l}\text { Dominican } \\
\text { Republic }\end{array}$ & 2 & 40 & 41.012 & 11 & 69 & 4,321.359 & $6,107.273$ & $2,864.695$ & $8,639.854$ & 91.250 & 90.156 & 27.500 & 155 \\
\hline Venezuela & 3 & 41 & 9 & 32 & 50 & 6,769.904 & $4,115.016$ & $2,654.889$ & $10,884.920$ & 19.727 & 6.621 & 12.500 & 25.500 \\
\hline Europe & 20 & 77.580 & 65.260 & 2 & 211 & $9,762.767$ & $12,410.760$ & 26.458 & 45,000 & 72.503 & 97.723 & 1 & 375 \\
\hline Finland & 1 & 187 & (.) & (.) & (.) & 5,050 & $()$. & (.) & (.) & 35 & (.) & (.) & (.) \\
\hline France & 2 & 64.500 & 70.004 & 15 & 114 & $19,888.890$ & $25,298.710$ & 2,000 & $37,777.780$ & 89.500 & 113.844 & 9 & 170 \\
\hline Germany & 2 & 73.500 & 61.518 & 30 & 117 & 22,975 & $31,148.050$ & 950 & 45,000 & 56.250 & 44.194 & 25 & 87.5 \\
\hline Italy & 5 & 133 & 56.675 & 56 & 211 & 3,350 & 2,897.197 & 200 & 7,650 & 46.900 & 82.920 & 2 & 195 \\
\hline Poland & 2 & 27 & 5.657 & 23 & 31 & $15,358.150$ & $6,173.749$ & $10,992.650$ & $19,723.650$ & 292 & 117.380 & 209 & 375 \\
\hline Spain & 2 & 118 & 19.799 & 104 & 132 & 6,875 & 3,358.757 & 4,500 & 9,250 & 35.500 & 10.607 & 28 & 43 \\
\hline Sweden & 1 & 7 & (.) & (.) & (.) & 26.458 & (.) & (.) & (.) & 5 & (.) & (.) & (.) \\
\hline Switzerland & 1 & 77 & (.) & (.) & (.) & $13,122.680$ & (.) & (.) & (.) & 82.500 & (.) & (.) & (.) \\
\hline $\begin{array}{l}\text { United } \\
\text { Kingdom }\end{array}$ & 4 & 11.250 & 9.878 & 2 & 22 & 1,218.721 & $1,384.308$ & 50.386 & 2,972 & 9.875 & 12.625 & 1 & 28 \\
\hline Total & 40 & 51.898 & 53.930 & 1 & 211 & $6,369.434$ & $9,373.714$ & 26.458 & 45,000 & 55.737 & 74.369 & 1 & 375 \\
\hline
\end{tabular}

${ }^{a}$ Companies were asked to report their annual revenues in their local currency. This amount was converted to euros based on the annual average rate reported by the Central

Bank of Spain, Banco de España (2018).

(.) not available 


\subsection{Data analysis}

The Partial Least Squares (PLS) approach to Structural Equation Modeling (SEM) was selected to test the model using 'SmartPLS 3.' (Ringle et al., 2015). This technique is preferable to other covariance-based methods because: i) it does not assume any distribution of the data, and ii) it is suitable for exploratory research based on small samples (Chin, 1998).

\section{3. $\quad$ Measurement of the Variables}

\subsubsection{Integration of management systems}

Researchers have commonly based on the integration of certified MSs to measure IMS (Bernardo et al., 2017; Ramos et al., 2018). However, companies can implement and integrate non-certified MSs and, moreover, IMS is non-certifiable yet at the international level (Gianni et al., 2017). According to the survey of this research, holding a certified MSs is not common among candle manufacturers. Even if $72.5 \%$ of the sample applied at least one MS (out of the four studied), only $22.5 \%$ hold at most one certification (mostly a QMS). Thus, a measure of IMS was constructed based on the existing literature as follows.

The basis of IMS lays on the importance given to MSs at the top-management level, which determines IMS for the whole organization (Bernardo et al., 2017; Gianni et al., 2017; Gianni and Gotzamani, 2015; Zeng et al., 2007). Based on this argument, IMS is measured as a construct composed of two variables that depend on the importance given to MSs by the top-management: IMS-breadth and IMS-depth. These measurements were adapted from the widely used definitions proposed by Laursen and Salten (2006) in the Open Innovation literature. More specifically, IMSbreadth is defined as the accumulated importance of all the individual MSs for representing how broad they are applied across the organization, (i.e., how spread can their IMS be applied). So:

IMS-breath = QMS_importance + EMS_importance + OHSMS_importance + CSR_importance

where the importance of each MS was coded as 0 'not relevant', 1 'Low', 2 'Medium' and 3 'Highly important'. Therefore, companies that consider 'Not relevant' all of the MSs have an IMSbreadth equal to zero, while those considering all (four) MSs 'Highly important' punctuate 12.

Next, IMS-depth is defined as the number of MSs considered highly important, suggesting how internalized are those MSs. To measure IMS-depth, firstly, each of the four MSs was coded as a binary variable equal to one such MS was 'Highly important' to the top-management and zero otherwise, and then, they were added up. Thus, IMS-depth equals zero when firms do not consider 
highly important any of the MSs, while it scores four if all the MSs are considered highly important (i.e., how deeply can their IMS be internalized).

\subsubsection{The adoption of cleaner production technologies}

CP technologies are a specific kind of process innovations (Kemp and Volpi, 2008) that occur in organizations moving towards CP (Mustapha et al., 2017; Ramos et al., 2018; Vieira and Amaral, 2016), so firms were firstly explained the 'process innovation' definition in accordance to the OECD (2005). Then, firms were asked if they introduced any process innovation during 2014-15, in which case they were asked to specify in which technology they innovated. Finally, they were asked to assess the importance of those innovations to: i) control pollution (cpt1), ii) have zero emissions out of their manufacturing processes (cpt2), and iii) reduce wastes such as energy and raw materials (cpt3) (CIS, 2012; Gavronski et al., 2012; Kemp and Volpi, 2008; Severo et al., 2015). Regarding firms that did not introduce any process innovation, it could be reasonably assumed that their processes did not change during 2014-15, so CPT1, CPT2 and CPT3 were classified as 'Not relevant'.

\subsubsection{Sustainable product innovation}

Firms were firstly introduced to the 'product innovation' definition according to the OECD (2005) and asked whether they introduced any during 2014-15. Firms that answered in the affirmative way were then asked to assess the importance of such innovations related to the technical and sustainable dimensions. Firstly, the main technical aspects of a candle were assessed. According to the pre-testing, the selected variables were the introduction or improvement of: i) waxes (pi1), ii) fragrances (pi2), and iii) colors/lacquers (pi3) (Derudi et al., 2012; ECA, 2017; NCA, 2017; Orecchio, 2011). Then, the importance of environmental care (pi4) and social responsibility (pi5) in the development of new products were asked to assess the sustainable dimensions of product innovation. These dimension were chosen since several studies warn that candles could be a source of indoor pollution, which could potentially produce negative effects on health (Ahn et al., 2015; Knight et al., 2001).

If companies did not introduce any product innovation, it could be reasonably assumed that no improved or new products were introduced, so the abovementioned indicators were classified as 'Not relevant'. In other words, since products remained the same during 2014-15, any improvement or introduction of new products was relevant.

\subsubsection{Control variables}

This sample consists of Latin-American and European firms, which could condition the results of adopting CP technologies and product innovation (Frondel et al., 2007). Thus, the continent was 
applied as a control variable coded as zero for Latin-American and one for European companies. As a dichotomous variable, it was immediately used as an indicator in the PLS-SEM model (Henseler et al., 2016). Finally, the revenues and age of companies were included as proxies of the structural characteristics of companies that might be related to sustainable innovations (Díaz-García et al., 2015).

\section{Results}

In this section, firstly, the general results related to the importance of the individual MSs and of the IMS indicators are presented, followed by the types of technological process innovations adopted by candle manufacturers. Then, the PLS-SEM results are presented, consisting of the measurement model and the structural model.

\subsection{Results of the management systems importance and integration}

Table 2 summarizes the MSs importance and IMS-breath and -depth results across the 40 valid responses. Regarding the importance of MSs, candle manufacturers give the highest importance to QMSs, followed by OHSMSs, EMSs and finally CSR. Regarding the IMS indicators, the IMSbreadth mean of 8.75 (out of 12) suggests that candle manufacturers integrated their MSs broadly, which seems to corroborate the idea that companies not necessarily have to be certified to integrate MSs. Moreover, the mean of IMS-depth is 2.050 (the maximum punctuation is four). This outcome suggests that, on average, companies integrated in depth, or internalized, two MSs, mainly QMSs and OHSMSs. More specifically, firms deeply internalized QMSs (75.00\%), followed by OHSMSs (55.00\%), EMSs (37.50\%) and CSR (37.50\%).

Table 2. MSs importance/integration statistics and Pearson correlations $(\mathrm{N}=40)$

\begin{tabular}{|c|c|c|c|c|c|c|c|c|c|c|}
\hline & Variable & Mean & Median & SD & 1 & 2 & 3 & 4 & 5 & 6 \\
\hline \multirow{4}{*}{ 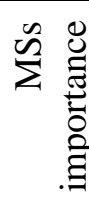 } & 1. QMS & 2.625 & 3 & 0.774 & 1 & & & & & \\
\hline & 2. EMS & 1.975 & 2 & 1.049 & 0.556 & 1 & & & & \\
\hline & 3. OHSMS & 2.275 & 3 & 0.987 & 0.676 & 0.650 & 1 & & & \\
\hline & 4. CSR & 1.875 & 2 & 1.090 & 0.490 & 0.535 & 0.629 & 1 & & \\
\hline \multirow{2}{*}{$\sum_{i}^{\infty}$} & 5. IMS-breadth & 8.750 & 9 & 3.248 & 0.788 & 0.833 & 0.886 & 0.816 & 1 & \\
\hline & 6. IMS-depth & 2.050 & 2 & 1.431 & 0.619 & 0.701 & 0.753 & 0.727 & 0.847 & 1 \\
\hline
\end{tabular}

All correlations are significant at $\mathrm{p}<0.01$ 


\subsection{Process innovation results}

Regarding process innovations, 75\% of the companies (30 out of 40) declared that they innovated in at least one process during 2014-15. As shown in Figure 2, most of the companies innovated in new packing solutions, molding (mainly in Latin-America) and filling. On average, companies that innovated in process, adopted between one and two innovations during this two-year period.

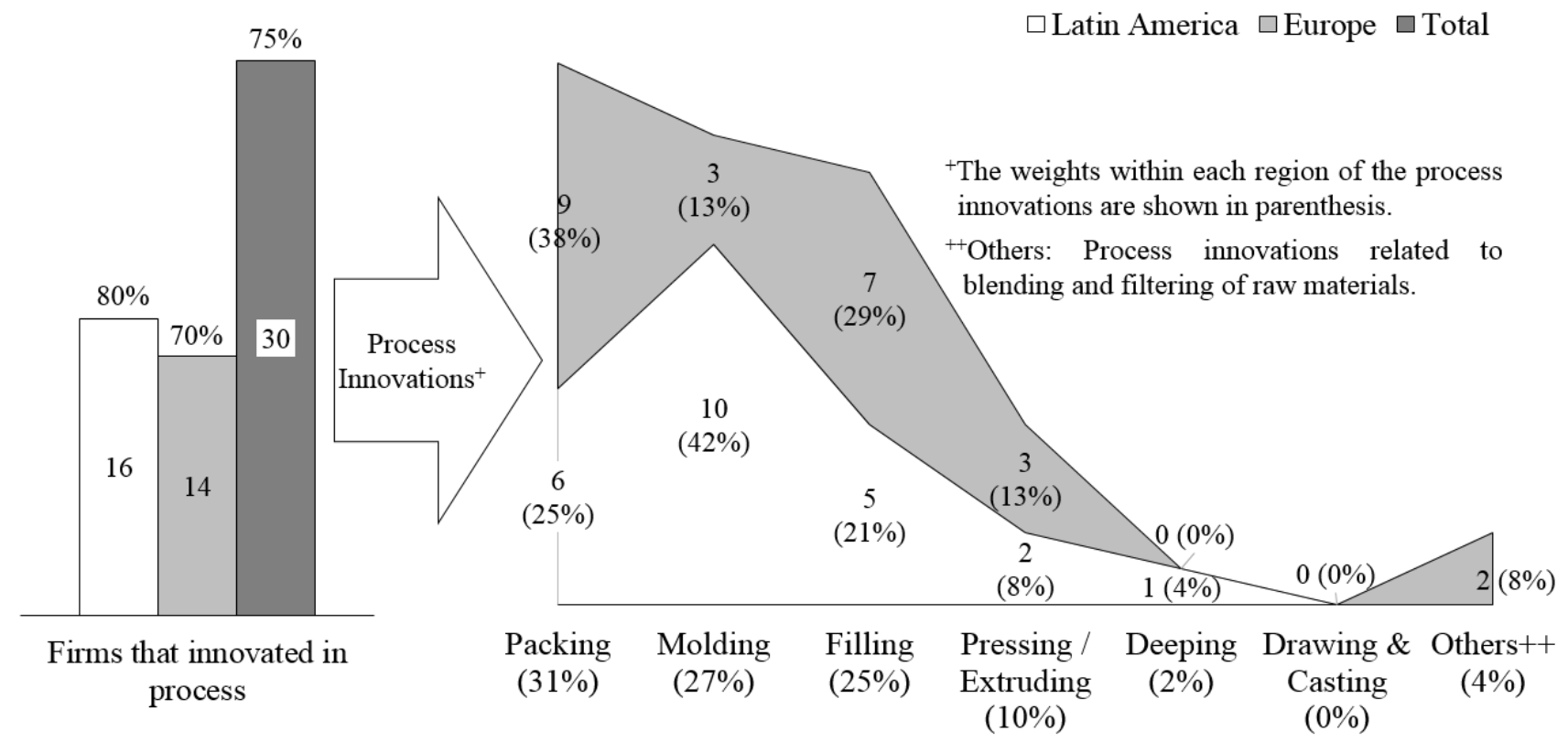

Figure 2. Process Innovations in the candle industry $(\mathrm{N}=40)$

\subsection{PLS-SEM results}

In this section, firstly the measurement model results is presented, followed by the structural model.

\subsubsection{Measurement model}

In PLS-SEM models, the reliability and validity of the measurement model are firstly assessed (Hair et al., 2011). Table 3 shows the results for measuring construct reliability and validity. For all the constructs, the values of the Cronbach’s alpha (Hair et al., 2016), coefficient Dijkstra-Henseler Rho_A (Dijkstra and Henseler, 2015) and composite reliability (Nunnally, 1967) are above the minimum value of 0.7 , so results show internal consistency reliability. Moreover, the Average Variance Extracted (AVE) is above the suggested 0.5 threshold (Hair et al., 2011), which evidences an acceptable level of convergent validity.

Table 3. Construct reliability and validity

Cronbach's Rho_A Composite AVE




\begin{tabular}{lcccc}
\hline & Alpha & \multicolumn{3}{c}{ Reliability } \\
\hline IMS & 0.917 & 0.952 & 0.960 & 0.922 \\
CP technologies & 0.890 & 0.904 & 0.931 & 0.818 \\
Sustainable product innovation & 0.936 & 0.954 & 0.951 & 0.796 \\
\hline
\end{tabular}

Table 4 shows the results for assessing discriminant validity. According to the Fornell-Larcker criterion that requires the square root of AVE to be larger than the inter-factor correlations (Fornell and Larcker, 1981; Hair et al., 2011), discriminant validity has been stablished between constructs. Moreover, the Heterotrait-monotrait (HTMT) ratio of correlations is smaller than the suggested threshold of 0.85 for all constructs (Henseler et al., 2015). Finally, the cross loading discriminant validity that requires each indicator to load the highest, and above 0.70 , on its corresponding LV (Carmines and Zeller, 1979; Hair et al., 2011) is met.

Table 4. Discriminant validity

\begin{tabular}{lcccccc}
\hline & 1 & 2 & 3 & 4 & 5 & 6 \\
\hline Fornell-Larcker criterion & & & & & & \\
1. IMS & 0.960 & & & & & \\
2. CP technologies & 0.307 & 0.905 & & & & \\
3. Sustainable product innovation & 0.270 & 0.477 & 0.892 & & & \\
4. Continent & 0.000 & -0.130 & -0.030 & 1.000 & & \\
5. Revenues & -0.028 & 0.237 & 0.044 & 0.303 & 1.000 & \\
6. Age & -0.185 & -0.128 & -0.244 & 0.487 & 0.336 & 1.000 \\
HTMT ratio of correlations & & & & & & \\
1. IMS & & & & & & \\
2. CP technologies & - & & & & & \\
3. Sustainable product innovation & 0.331 & - & & & & \\
4. Continent & 0.279 & 0.484 & - & & & \\
5. Revenues & 0.000 & 0.149 & 0.065 & - & & \\
6. Age & 0.043 & 0.238 & 0.080 & 0.296 & - & \\
Cross loadings & 0.189 & 0.143 & 0.259 & 0.487 & 0.331 & - \\
ims_breath & & & & & & \\
ims_depth & & & & & & \\
cpt1 & $\mathbf{0 . 9 5 1}$ & 0.281 & 0.201 & 0.000 & 0.013 & -0.141 \\
cpt2 & $\mathbf{0 . 9 6 9}$ & 0.306 & 0.307 & -0.000 & -0.066 & -0.208 \\
cpt3 & 0.337 & $\mathbf{0 . 8 7 2}$ & 0.524 & 0.000 & 0.270 & -0.021 \\
pi1 & 0.244 & $\mathbf{0 . 8 9 3}$ & 0.324 & -0.184 & 0.176 & -0.136 \\
pi2 & 0.235 & $\mathbf{0 . 9 4 7}$ & 0.415 & -0.197 & 0.163 & -0.209 \\
pi3 & 0.166 & 0.272 & $\mathbf{0 . 8 5 3}$ & -0.074 & -0.049 & -0.314 \\
pi4 & 0.242 & 0.283 & $\mathbf{0 . 9 0 2}$ & 0.036 & -0.053 & -0.208 \\
pi5 & 0.204 & 0.535 & $\mathbf{0 . 8 7 3}$ & -0.095 & 0.114 & -0.190 \\
continent & 0.239 & 0.418 & $\mathbf{0 . 9 4 2}$ & -0.036 & 0.042 & -0.241 \\
revenues & 0.327 & 0.522 & $\mathbf{0 . 8 8 8}$ & 0.038 & 0.088 & -0.168 \\
age & -0.000 & -0.130 & -0.030 & $\mathbf{1 . 0 0 0}$ & 0.296 & 0.487 \\
\hline & -0.032 & 0.230 & 0.045 & 0.296 & $\mathbf{1 . 0 0 0}$ & 0.331 \\
sqareroots of AVE are & -0.185 & -0.128 & -0.244 & 0.487 & 0.331 & $\mathbf{1 . 0 0 0}$ \\
\hline
\end{tabular}

The square roots of AVE are shown in the diagonal of the Fornell-Larcker criterion

The loadings of the LV corresponding to each indicator are shown in bolds in the cross loadings. 


\subsubsection{Structural Model}

The $R^{2}$ of the endogenous constructs is recommended to be $\geq 0.1$ (Falk and Miller, 1992: 80). This criterion is accomplished for both, the adoption of CP technologies $\left(\mathrm{R}^{2}=0.202\right)$ and sustainable product innovation $\left(\mathrm{R}^{2}=0.288\right)$. Moreover, according to Henseler et al. (2016), the only approximate model fit criterion implemented for PLS path modeling is the Standardized Root Mean Square Residual (SRMR). The SRMR is therefore a goodness of fit measure for PLS-SEM that can be used to avoid model misspecification, for which its value should be below 0.080 (Hu and Bentler, 1998). This criterion is met for both the saturated model (SRMR = 0.052) and for the estimated model (SRMR = 0.053).

Table 5 summarizes the significances and coefficients of the direct and indirect effects. According to the results, hypotheses $\mathrm{H} 1$ and $\mathrm{H} 2$ are supported, in contrast to $\mathrm{H} 3$ that is not supported. In the latter case, even if there is a positive relationship between IMS and sustainable product innovation (mediated by the adoption of CP technologies), this relationship is not significant at $p<0.05$. Regarding control variables, results suggest that continent does not have a significant role towards the adoption of CP technologies nor to sustainable product innovation. The latter seems to be more related to younger companies, but the effect of age on sustainable product innovation is not significant. Moreover, results evidence that the adoption of CP technologies is significantly influenced by revenues, so bigger companies seem to be more prone to adopt these technologies. Finally, revenues do not have a significant role to sustainable product innovation, as well as the age of companies is not related to the adoption of cleaner production technologies according to the results.

Table 5. Results of the bootstrapping with 5,000 sub-samplings

\begin{tabular}{lccl}
\hline & Coefficient & T Statistics & Conclusion \\
\hline Direct effects & & & \\
IMS $\rightarrow$ CP tech. & $0.300^{*}$ & 2.050 & H2 \\
& $(0.146)$ & & supported \\
IMS $\rightarrow$ Sustainable Product Innovation & 0.090 & 0.536 & \\
& $(0.168)$ & & \\
CP tech. $\rightarrow$ Sustainable Product Innovation & $0.442^{*}$ & 2.487 & H1 \\
& $(0.178)$ & & supported \\
Indirect effects & & & \\
IMS $\rightarrow$ CP tech. $\rightarrow$ Sustainable Product Innovation & $0.133^{\dagger}$ & 1.601 & H3 not \\
& $(0.083)$ & & supported \\
Control variables direct and indirect effects & & & \\
Continent $\rightarrow$ CP tech. & -0.182 & 0.972 & \\
Continent $\rightarrow$ Sustainable Product Innovation & $(0.187)$ & & \\
& 0.150 & 0.810 & \\
Revenues $\rightarrow$ CP tech. & $(0.185)$ & & \\
\hline
\end{tabular}




\begin{tabular}{lcc}
\hline & $(0.151)$ & \\
Revenues $\rightarrow$ Sustainable Product Innovation & -0.020 & 0.116 \\
Age $\rightarrow$ CP tech. & $(0.174)$ & \\
& -0.091 & 0.537 \\
Age $\rightarrow$ Sustainable Product Innovation & $(0.170)$ & \\
& $-0.237^{\dagger}$ & 1.503 \\
Continent $\rightarrow$ CP tech. $\rightarrow$ Sustainable Product Innovation & $(0.158)$ & -0.080 \\
& $(0.095)$ & 0.841 \\
Revenues $\rightarrow$ CP tech. $\rightarrow$ Sustainable Product Innovation & $0.143^{\dagger}$ & 1.592 \\
& $(0.090)$ & \\
Age $\rightarrow$ CP tech. $\rightarrow$ Sustainable Product Innovation & -0.040 & 0.530 \\
& $(0.076)$ &
\end{tabular}

Finally, Figure 3 illustrates the endogenous variables’ R-squared and the path coefficients with its significance levels, which are of particular relevance to exploratory studies (Henseler, 2018).

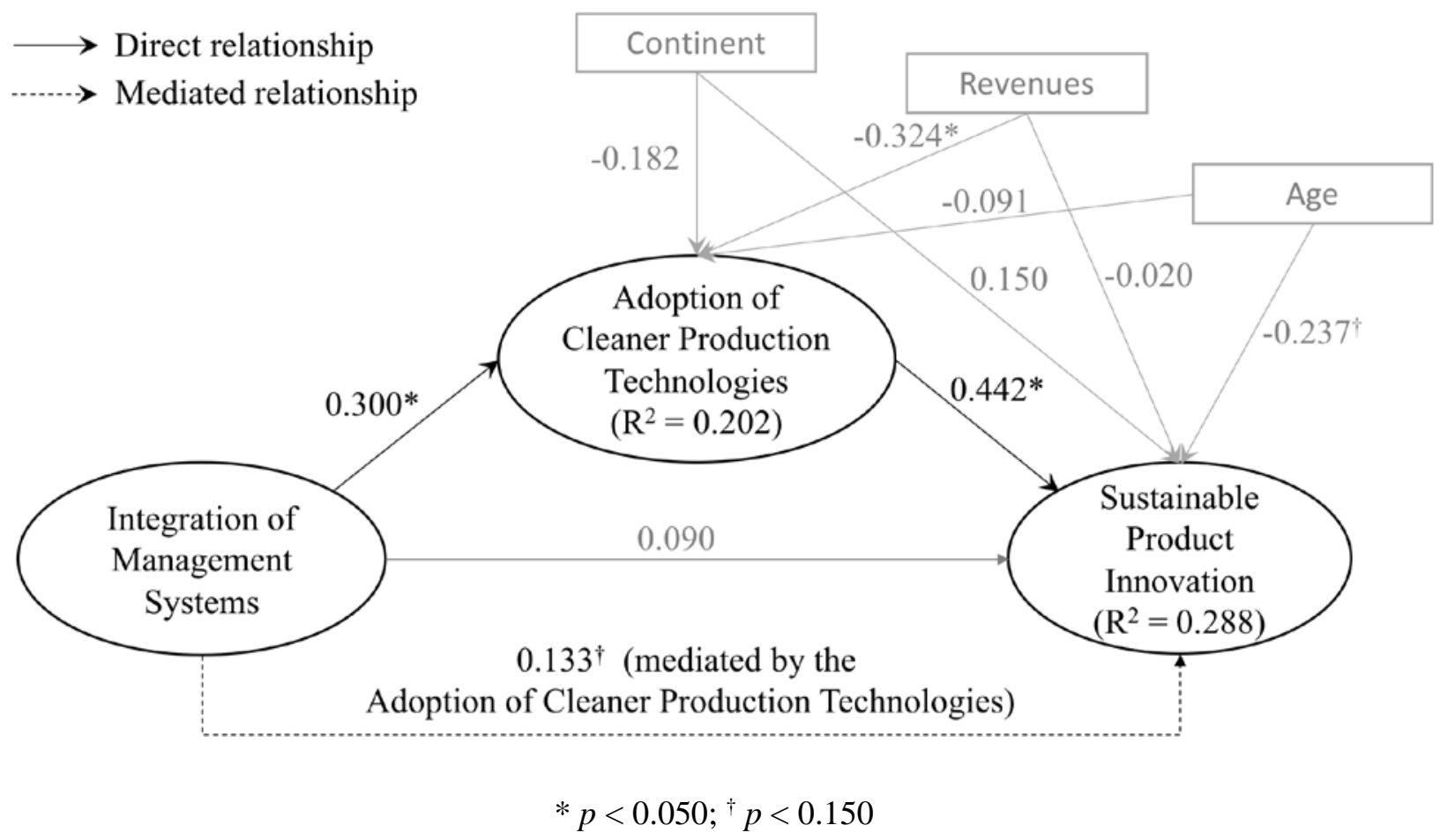

Figure 3. Results of the model relating IMS and sustainable innovation

\section{Discussion}

According to the results, adopting CP technologies is positively related to sustainable product innovation, which supports $\mathrm{H} 1$. This result is in line with previous research suggesting that companies should radically switch their internal operations to reduce any pollution or social effects at source (Boons et al., 2013) to subsequently create sustainable products aiming to integrate the 
technical, environmental and social implications (Rebelo et al., 2016). Only then, companies would have a real focus on the objectives of cleaner production, which aims to minimize the environmental and social impacts (Kemp and Volpi, 2008; UNEP DTIE, 1996; Vieira and Amaral, 2016).

To test hypotheses H2 and H3, firstly, IMS was measured objectively. The IMS-breadth and IMSdepth indicators were introduced in this study based on the widely used definitions proposed by Laursen and Salten (2006). Both IMS-breadth and IMS-depth are overall measures of the extent at which MSs are integrated at the strategic level, based on the importance given to all MSs by the top-management (Bernardo et al., 2017; Gianni et al., 2017; Gianni and Gotzamani, 2015; Zeng et al., 2007). The higher the IMS-breadth and IMS-depth, the broader (spread) and deeper (internalized) is the IMS. This methodological contribution allows to have an IMS proxy even when MSs are not formally certified, so it complements other approaches regarding the difficulty of assessing IMS (Gianni et al., 2017).

Based on the previous measurement of IMS, a positive and significant relationship is evidenced between IMS and the adoption of CP technologies, which supports hypothesis H2. This suggests that IMS not only fosters process innovations (Bernardo, 2014; Hernandez-Vivanco et al., 2016; Simon and Petnji Yaya, 2012), but it also provides the necessary strategical support so that such innovations are sustainable (Gianni et al., 2017). Particularly, IMS fosters the elimination of pollution and social effects (including workforce) at source. This result is in good agreement with the cleaner production objectives, as concluded in Vieira and Amaral (2016) and Mustapha et al. (2017). This finding is of particular relevance given the open-ended debate of whether IMS supports sustainability-oriented practices. As reported by Ramos et al. (2018), IMS seems to be closely related to the adoption of CP-related practices. However, the authors also found that, even if this positive relationship happens in most cases, a minority of companies that adopted multiple certifications applied CP-related practices (only) to a limited extent. The authors clarify that in those cases, companies sought to satisfy the requirements of the multiple stakeholders. However, they failed to report the importance of such companies to meet those requirements. Thus, IMS measured just as the adoption of multiple certifications might not be a reliable indicator. The IMS measures proposed in this manuscript might complement others based on standardized MSs (see e.g., Abad et al., 2014; Bernardo et al., 2009). In spite of such methodological differences, the positive relationship between IMS and the adoption of CP technologies is also observed, which is in good agreement with the existing literature (Mustapha et al., 2017; Ramos et al., 2018; Vieira and Amaral, 2016). 
Moreover, it is evidenced that IMS does not have a significant effect on sustainable product innovation and thus, H3 is not supported. According to the results, even if the coefficient of the indirect path, mediated by the adoption of CP technologies, is positive, its $p$-value (0.109) shows very little (if any) effect on sustainable product innovation. This outcome suggests that, even if IMS might foster product innovation (Hernandez-Vivanco et al., 2016; Simon and Petnji Yaya, 2012), more efforts, beyond the adoption of CP technologies, are required to accomplish a sustainability approach in the development of new products. These results are in accordance with Ramos et al. (2018) who found that IMS might foster CP-oriented practices, but that, still, companies carried out very few structural modifications in the products seeking to reduce environmental impact. Therefore, there might be relevant differences between sustainable innovation and innovation in general that should be further explored (del Río et al., 2016). In this effort, IMS as internal factor might have significant interactions with the assimilation of external knowledge in companies that adopt open innovation strategies (Hernandez-Vivanco et al., 2016). Thus, further research might explore more complex relationships and mediators relating internal (IMS) and external (open innovation) factors. In fact, there are still major gaps in literature to understand how organizations systematically learn and embed external knowledge towards sustainable innovation (Kennedy et al., 2017; Watson et al., 2018). Hence, future research might deem the findings of this manuscript to include IMS as part of the organizational systematic practices involved in this debate.

Finally, the effects of control variables are discussed as follows. Regarding the effect of location, it is evidenced that both Latin-American and European companies have similar results, as opposite to other studies that have reported some differences between countries (Frondel et al., 2007). Therefore, IMS seems to promote sustainable innovation irrespective of companies' location. This fact might be attributed to the isomorphism across organizations promoted by IMS, achieved through the homogenous and high internalization of all the MSs' objectives (Bernardo et al., 2017; Gianni et al., 2017; Gianni and Gotzamani, 2015; Zeng et al., 2007). To this end, the topmanagement is required to be highly committed with all the MSs and with its integration (Bernardo et al., 2017). Moreover, it is observed that younger companies seem to be more inclined (but not significantly so) to developing sustainable product innovations. However, the age of companies seems not to have any significant role on the adoption of CP technologies. Furthermore, the size of companies in terms of revenues is evidenced to affect significantly the adoption of CP technologies as bigger companies have more resources to invest in new technologies. Nonetheless, the role of revenues towards sustainable product innovation seems to be limited and, at most, mediated by the adoption of CP technologies. These results are in line with del Río et al. (2017) who focused on studying these relationships in depth. 


\section{Conclusions}

The aim of this article is to explore whether the integration of management systems acts as a driver of sustainable innovation in developed and developing countries, within the framework of cleaner production. To this end, the relationships between IMS, the adoption of CP technologies and sustainable product innovation were analyzed. Results suggest that the involvement of the topmanagement in the application and internalization of QMSs, EMSs, OHSMSs and CSR is critical to promote IMS. This, in turn, might foster the adoption of CP technologies, which seems to be closely related to sustainable product innovation. However, the mediated effect of IMS on sustainable product innovation is limited and requires of further research.

This study has three main implications for academia. Firstly, IMS-breadth and IMS-depth were introduced in this study as overall IMS measures to complement other approaches mainly based on certified MSs. Secondly, there seem not to be any significant differences regarding companies’ location to perform sustainable innovations. In this regard, IMS might play a relevant role to promote isomorphism across organizations, achieved through the homogenous and high internalization of all the MSs' objectives. Finally, this study evidences that there might be differences in the relationship between IMS and sustainable innovation vs. IMS and innovation in general, specially regarding product innovation.

The main implication to practitioners lays on the importance given to the deep and broad IMS in companies involved in the debate of indoor pollution, regardless of their location. More specifically, IMS might provide the managerial support to adopt CP technologies not only to meet the requirements of formal regulations. This might have benefits beyond the improvement of the manufacturing process. More specifically the adoption of CP technologies seems to be closely related to the development of sustainable products. This implicates innovating with a long-term perspective by continuously improving the technical, environmental and social aspects of new products.

Regarding the contribution of this research, this is one of the first studies to relate empirically IMS, the adoption of CP technologies and product innovation in pursue of sustainability based on a crosscountry sample that includes developed, middle-income and developing countries. It also contributes to literature by shedding light on the importance of IMS to promote the reduction of indoor pollution at the manufacturing process and thus, potentially benefiting consumers' health from the sustainable management perspective.

Despite its contributions, this article has some limitations. It is an exploratory study of the current status of candle manufacturers and results shall be interpreted with caution. Moreover, the 
conclusions apply to candle manufacturers related to the most representative European and LatinAmerican candle associations, so other firms or from other industries and regions might not be represented.

Further research will focus on measuring the real effects of candles comparing the emission of potentially dangerous substances of companies that have adopted IMS vs. those that have not. Future research might also confirm the exploratory results of this paper using larger samples, more complex relationships including open innovation, more control variables and both qualitative and quantitative longitudinal studies. Other countries that are putting industry as a major priority of their political agendas should also be studied, including the United States, India, China, among others. Finally, further research might consider IMS and innovation as potential promotors of sustainable development in other industries involved in the debate of indoor and outdoor pollution.

\section{References}

Abad, J., Dalmau, I., Vilajosana, J., 2014. Taxonomic proposal for integration levels of management systems based on empirical evidence and derived corporate benefits. J. Clean. Prod. 78, 164-173. doi:10.1016/j.jclepro.2014.04.084

Ahn, J.H., Kim, K.H., Kim, Y.H., Kim, B.W., 2015. Characterization of hazardous and odorous volatiles emitted from scented candles before lighting and when lit. J. Hazard. Mater. 286, 242-251. doi:10.1016/j.jhazmat.2014.12.040

Banco de España, 2018. Interest rates and exchange rates [WWW Document]. URL https://www.bde.es/webbde/en/estadis/infoest/tipos/tipos.html (accessed 3.20.18).

Bernardo, M., 2014. Integration of management systems as an innovation: a proposal for a new model. J. Clean. Prod. 82, 132-142. doi:10.1016/j.jclepro.2014.06.089

Bernardo, M., Casadesus, M., Karapetrovic, S., Heras, I., 2009. How integrated are environmental, quality and other standardized management systems? An empirical study. J. Clean. Prod. 17, 742-750. doi:10.1016/j.jclepro.2008.11.003

Bernardo, M., Gianni, M., Gotzamani, K., Simon, A., 2017. Is there a common pattern to integrate multiple management systems? A comparative analysis between organizations in Greece and Spain. J. Clean. Prod. 151, 121-133. doi:10.1016/j.jclepro.2017.03.036

Bonilla, S.H., Almeida, C.M.V.B., Giannetti, B.F., Huisingh, D., 2010. The roles of cleaner production in the sustainable development of modern societies: an introduction to this special 
issue. J. Clean. Prod. 18, 1-5. doi:10.1016/j.jclepro.2009.09.001

Boons, F., Montalvo, C., Quist, J., Wagner, M., 2013. Sustainable innovation, business models and economic performance: an overview. J. Clean. Prod. 45, 1-8. doi:10.1016/j.jclepro.2012.08.013

Bottani, E., Monica, L., Vignali, G., 2009. Safety management systems: Performance differences between adopters and non-adopters. Saf. Sci. 47, 155-162. doi:10.1016/j.ssci.2008.05.001

Carmines, E.G., Zeller, R.A., 1979. Reliability and Validity Assessment. Sage publications, Newbury Park, CA.

Chin, W.W., 1998. The partial least squares approach to structural equation modeling. Mod. methods Bus. Res. 295-336.

CIS, 2012. The Community Innovation Survey 2012. Eurostat 2012.

ComRes/AECM, 2015. Research into the European Candles Market [WWW Document]. URL http://europecandles.org/uploads/kcFinder/files/aecm-2015-comres-executive-summary.pdf (accessed 7.30.16).

Darnall, N., Jolley, G.J., Handfield, R., 2008. Environmental management systems and green supply chain management: complements for sustainability? Bus. Strateg. Environ. 17, 30-45. doi:10.1002/bse.557

del Río, P., Peñasco, C., Romero-Jordán, D., 2016. What drives eco-innovators? A critical review of the empirical literature based on econometric methods. J. Clean. Prod. 112, 2158-2170. doi:10.1016/j.jclepro.2015.09.009

del Río, P., Romero-Jordán, D., Peñasco, C., 2017. Analysing firm-specific and type-specific determinants of eco-innovation. Technol. Econ. Dev. Econ. 23, 270-295. doi:10.3846/20294913.2015.1072749

Derudi, M., Gelosa, S., Sliepcevich, A., Cattaneo, A., Rota, R., Cavallo, D., Nano, G., 2012. Emissions of air pollutants from scented candles burning in a test chamber. Atmos. Environ. 55, 257-262. doi:10.1016/j.atmosenv.2012.03.027

Díaz-García, C., González-Moreno, Á., Sáez-Martínez, F.J., 2015. Eco-innovation: insights from a literature review. Innov. Manag. Policy Pract. 17, 6-23. doi:10.1080/14479338.2015.1011060

Dijkstra, T.K., Henseler, J., 2015. Consistent Partial Least Squares Path Modeling. MIS Q. 39, 297316. doi:10.25300/MISQ/2015/39.2.02

ECA, 2017. European Candle Association [WWW Document]. URL http://www.eca-candles.com 
(accessed 2.22.17).

Elkington, J., 1997. Partnerships from Cannibals with Forks: The Triple Bottom line of 21 st Century Business. Environ. Qual. Manag. Autumn 199, 37-51. doi:10.1002/tqem.3310080106

Esquer-Peralta, J., Velazquez, L., Munguia, N., 2008. Perceptions of core elements for sustainability management systems (SMS). Manag. Decis. 46, 1027-1038. doi:10.1108/00251740810890195

Faraday, M., 2001. The Chemical History of a Candle. Bartleby.com, New York, NY.

Fornell, C., Larcker, D.F., 1981. Evaluating Structural Equation Models with Unobservable Variables and Measurement Error. J. Mark. Res. 18, 39. doi:10.2307/3151312

Frondel, M., Horbach, J., Rennings, K., 2007. End-of-pipe or cleaner production? An empirical comparison of environmental innovation decisions across OECD countries. Bus. Strateg. Environ. 16, 571-584. doi:10.1002/bse.496

Gavronski, I., Klassen, R.D., Vachon, S., Machado do Nascimento, L.F., 2012. A learning and knowledge approach to sustainable operations. Int. J. Prod. Econ. 140, 183-192. doi:10.1016/j.ijpe.2012.01.037

Gianni, M., Gotzamani, K., 2015. Management systems integration: lessons from an abandonment case. J. Clean. Prod. 86, 265-276. doi:10.1016/j.jclepro.2014.08.023

Gianni, M., Gotzamani, K., Tsiotras, G., 2017. Multiple perspectives on integrated management systems and corporate sustainability performance. J. Clean. Prod. 168, 1297-1311. doi:10.1016/j.jclepro.2017.09.061

Hair, J., Celsi, M., Money, A., Samouel, P., Page, M., 2016. Essentials of Business Research Methods, 3rd ed. ed. Routledge, New York, NY.

Hair, J.F., Ringle, C.M., Sarstedt, M., 2011. PLS-SEM: Indeed a Silver Bullet. J. Mark. Theory Pract. 19, 139-152. doi:10.2753/MTP1069-6679190202

Henseler, J., 2018. Partial least squares path modeling: Quo vadis? Qual. Quant. 52, 1-8. doi:10.1007/s11135-018-0689-6

Henseler, J., Hubona, G., Ray, P.A., 2016. Using PLS path modeling in new technology research: updated guidelines. Ind. Manag. Data Syst. 116, 2-20. doi:10.1108/IMDS-09-2015-0382

Henseler, J., Ringle, C.M., Sarstedt, M., 2015. A new criterion for assessing discriminant validity in variance-based structural equation modeling. J. Acad. Mark. Sci. 43, 115-135. doi:10.1007/s11747-014-0403-8 
Hernandez-Vivanco, A., Bernardo, M., Cruz-Cázares, C., 2016. Relating open innovation, innovation and management systems integration. Ind. Manag. Data Syst. 116, 1540-1556. doi:10.1108/IMDS-09-2015-0405

Hoang, D.T., Igel, B., Laosirihongthong, T., 2006. The impact of total quality management on innovation: Findings from a developing country. Int. J. Qual. Reliab. Manag. 23, 1092-1117. doi:10.1108/02656710610704230

Hu, L.T., Bentler, P.M., 1998. Fit Indices in Covariance Structure Modeling: Sensitivity to Underparameterized Model Misspecification. Psychol. Methods 3, 424-453. doi:10.1037/1082-989X.3.4.424

ISO, 2018. aManagement system standards [WWW Document]. URL https://www.iso.org/management-system-standards.html (accessed 2.15.18).

Jørgensen, T.H., 2008. Towards more sustainable management systems: through life cycle management and integration. J. Clean. Prod. 16, 1071-1080. doi:10.1016/j.jclepro.2007.06.006

Jørgensen, T.H., Remmen, A., Mellado, M.D., 2006. Integrated management systems - Three different levels of integration. J. Clean. Prod. 14, 713-722. doi:10.1016/j.jclepro.2005.04.005

Karataş, A.E., Gülder, Ö.L., 2012. Soot formation in high pressure laminar diffusion flames. Prog. Energy Combust. Sci. 38, 818-845. doi:10.1016/j.pecs.2012.04.003

Kemp, R., Volpi, M., 2008. The diffusion of clean technologies: a review with suggestions for future diffusion analysis. J. Clean. Prod. 16, 14-21. doi:10.1016/j.jclepro.2007.10.019

Kennedy, S., Whiteman, G., van den Ende, J., 2017. Radical Innovation for Sustainability: The Power of Strategy and Open Innovation. Long Range Plann. 50, 712-725. doi:10.1016/j.lrp.2016.05.004

Khanna, M., Deltas, G., Harrington, D.R., 2009. Adoption of pollution prevention techniques: The role of management systems and regulatory pressures. Environ. Resour. Econ. 44, 85-106. doi:10.1007/s10640-009-9263-y

Knight, L., Levin, A., Mendenhall, C., 2001. Candles and Incense as Potential Sources of Indoor Air Pollution: Market Analysis and Literature Review (EPA/600/R-01/001), EPA Research and Development. Washington, D.C.

Laursen, K., Salter, A., 2006. Open for innovation: The role of openness in explaining innovation performance among U.K. manufacturing firms. Strateg. Manag. J. 27, 131-150. doi:10.1002/smj.507 
Lim, S., Prakash, A., 2014. Voluntary regulations and innovation: The Case of ISO 14001. Public Adm. Rev. 74, 233-244. doi:10.1111/puar.12189

Lo, C.K.Y., Pagell, M., Fan, D., Wiengarten, F., Yeung, A.C.L., 2014. OHSAS 18001 certification and operating performance: The role of complexity and coupling. J. Oper. Manag. 32, 268280. doi:10.1016/j.jom.2014.04.004

Longoni, A., Cagliano, R., 2015. Environmental and social sustainability priorities. Int. J. Oper. Prod. Manag. 35, 216-245. doi:10.1108/IJOPM-04-2013-0182

Lozano, R., 2012. Towards better embedding sustainability into companies’ systems: An analysis of voluntary corporate initiatives. J. Clean. Prod. 25, 14-26. doi:10.1016/j.jclepro.2011.11.060

Lozano, R., Nummert, B., Ceulemans, K., 2016. Elucidating the relationship between Sustainability Reporting and Organisational Change Management for Sustainability. J. Clean. Prod. 125, 168-188. doi:10.1016/j.jclepro.2016.03.021

Manigrasso, M., Vitali, M., Protano, C., Avino, P., 2017. Temporal evolution of ultrafine particles and of alveolar deposited surface area from main indoor combustion and non-combustion sources in a model room. Sci. Total Environ. 598, 1015-1026. doi:10.1016/j.scitotenv.2017.02.048

Moreno-Luzon, M.D., Gil-Marques, M., Valls-Pasola, J., 2013. TQM, innovation and the role of cultural change. Ind. Manag. Data Syst. 113, 1149-1168. doi:10.1108/imds-02-2013-0075

Muñoz-Villamizar, A., Santos, J., Viles, E., Ormazábal, M., 2018. Manufacturing and environmental practices in the Spanish context. J. Clean. Prod. 178, 268-275. doi:10.1016/j.jclepro.2018.01.026

Mustapha, M.A., Manan, Z.A., Wan Alwi, S.R., 2017. Sustainable Green Management System (SGMS) - An integrated approach towards organisational sustainability. J. Clean. Prod. 146, 158-172. doi:10.1016/j.jclepro.2016.06.033

NCA, 2017. National Candle Association [WWW Document]. URL http://candles.org/ (accessed 2.22.17).

Nordhaus, W.D., 1996. Do Real-Output and Real-Wage Measures Capture Reality? The History of Lighting Suggests Not, in: Bresnahan, T.F., Gordon, R.J. (Eds.), The Economics of New Goods. University of Chicago Press, pp. 27-70.

Nunhes, T.V., Ferreira Motta, L.C., de Oliveira, O.J., 2016. Evolution of integrated management systems research on the Journal of Cleaner Production: Identification of contributions and gaps in the literature. J. Clean. Prod. 139, 1234-1244. doi:10.1016/j.jclepro.2016.08.159 
Nunnally, J.C., 1967. Psychometric theory. McGraw-Hill, New York, NY.

OECD, 2005. Oslo Manual: Guidelines for Collecting and Interpreting Innovation Data, 3rd Edition, The Measurement of Scientific and Technological Activities. OECD Publishing. doi:10.1787/9789264013100-en

Orecchio, S., 2011. Polycyclic aromatic hydrocarbons (PAHs) in indoor emission from decorative candles. Atmos. Environ. 45, 1888-1895. doi:10.1016/j.atmosenv.2010.12.024

Oskarsson, K., Malmborg, F., 2005. Integrated Management Systems as a Corporate Response to Sustainable Development. Corp. Soc. Responsib. Environ. Manag. 12, 121-128. doi:10.1002/csr.078

PITEC, 2007. Encuesta sobre innovación en las empresas 2007 [WWW Document]. URL https://www.fecyt.es/ (accessed 7.11.16).

Radonjič, G., Tominc, P., 2006. The impact and significance of ISO 14001 certification on the adoption of new technologies. Manag. Environ. Qual. An Int. J. 17, 707-727. doi:10.1108/14777830610702539

Ramos, A.R., Ferreira, J.C.E., Kumar, V., Garza-Reyes, J.A., Cherrafi, A., 2018. A lean and cleaner production benchmarking method for sustainability assessment: A study of manufacturing companies in Brazil. J. Clean. Prod. 177, 218-231. doi:10.1016/j.jclepro.2017.12.145

Rebelo, M.F., Santos, G., Silva, R., 2016. Integration of management systems: towards a sustained success and development of organizations. J. Clean. Prod. 127, 96-111. doi:10.1016/j.jclepro.2016.04.011

Ringle, C.M.., Wende, S.., Becker, J.-M., 2015. SmartPLS 3.

Rocha, M., Searcy, C., Karapetrovic, S., 2007. Integrating Sustainable Development into Existing Management Systems. Total Qual. Manag. Bus. Excell. 18, 83-92. doi:10.1080/14783360601051594

Salomone, R., 2008. Integrated management systems: experiences in Italian organizations. J. Clean. Prod. 16, 1786-1806. doi:10.1016/j.jclepro.2007.12.003

Santos, G., Barros, S., Mendes, F., Lopes, N., 2013. The main benefits associated with health and safety management systems certification in Portuguese small and medium enterprises post quality management system certification. Saf. Sci. 51, 29-36. doi:10.1016/j.ssci.2012.06.014

Severo, E.A., De Guimarães, J.C.F., Dorion, E.C.H., Nodari, C.H., 2015. Cleaner production, environmental sustainability and organizational performance: An empirical study in the 
Brazilian metal-mechanic industry. J. Clean. Prod. 96, 118-125. doi:10.1016/j.jclepro.2014.06.027

Simon, A., Petnji Yaya, L.H., 2012. Improving innovation and customer satisfaction through systems integration. Ind. Manag. Data Syst. 112, 1026-1043. doi:10.1108/02635571211255005

Siva, V., Gremyr, I., Bergquist, B., Garvare, R., Zobel, T., Isaksson, R., 2016. The support of Quality Management to sustainable development: a literature review. J. Clean. Prod. 138, 148157. doi:10.1016/j.jclepro.2016.01.020

Skovmand, A., Damiao Gouveia, A.C., Koponen, I.K., Møller, P., Loft, S., Roursgaard, M., 2017. Lung inflammation and genotoxicity in mice lungs after pulmonary exposure to candle light combustion particles. Toxicol. Lett. 276, 31-38. doi:10.1016/j.toxlet.2017.04.015

Sroufe, R., 2017. Integration and organizational change towards sustainability. J. Clean. Prod. 162, 315-329. doi:10.1016/j.jclepro.2017.05.180

Tarí, J.J., Molina-Azorín, J.F., 2010. Integration of quality management and environmental management systems. TQM J. 22, 687-701. doi:10.1108/17542731011085348

UNEP DTIE, 1996. Cleaner Production: a Resource Training Package, first ed. ed. United Nations Publication, Paris.

Vieira, L.C., Amaral, F.G., 2016. Barriers and strategies applying Cleaner Production: A systematic review. J. Clean. Prod. 113, 5-16. doi:10.1016/j.jclepro.2015.11.034

Wagner, M., 2007. Integration of Environmental Management with Other Managerial Functions of the Firm. Long Range Plann. 40, 611-628. doi:10.1016/j.lrp.2007.08.001

Watson, R., Wilson, H.N., Smart, P., Macdonald, E.K., 2018. Harnessing Difference: A CapabilityBased Framework for Stakeholder Engagement in Environmental Innovation. J. Prod. Innov. Manag. 35, 254-279. doi:10.1111/jpim.12394

Zeng, S.X., Shi, J.J., Lou, G.X.X., 2007. A synergetic model for implementing an integrated management system: an empirical study in China. J. Clean. Prod. 15, 1760-1767. doi:10.1016/j.jclepro.2006.03.007

Zwetsloot, G.I.J.M., 1995. Improving cleaner production by integration into the management of quality, environment and working conditions. J. Clean. Prod. 3, 61-66. doi:10.1016/09596526(95)00046-H 


\section{Appendix}

Questionnaire

Notes:

- This is a questionnaire that belongs to a larger survey. Below, all the items that were used in this study are shown.

- $\quad$ The sources for the design of each question is indicated below the corresponding entry.

- All participants were provided with the required definitions of management systems (ISO, 2018) and innovation (OECD, 2005).

- The scales of all the questions regarding the 'importance' or 'degree' was adapted from the CIS (2012). The codification is as follows: 0 "Not relevant”, 1 “Low”, 2 “Medium” and 3 "High”.

- The codes shown in questions 4, 7 and 9 were not included in the questionnaire.

General information

1. To what candle's associations is your company affiliated?

2. Job title(s)

3. In what country is your company currently headquartered?

Management Systems

4. During the two years 2014 and 2015, how important were each of the following management systems to your company?

\begin{tabular}{llllll}
\hline Code & Item & High & Medium & Low & Not relevant \\
\hline QMS & Quality & & & & \\
EMS & Environment & & & & \\
OHSMS & Operational Health and Safety & & & & \\
CSR & Corporate Social Responsibility & & & & \\
\hline
\end{tabular}

Source: Adapted from the Spanish Innovation Panel (PITEC, 2007) in which the innovation effects on Quality and Environment are included. The importance of OHSMS and CSR were incorporated for the assessment of IMS (see e.g., Jørgensen et al., 2006; Salomone, 2008; Zeng et al., 2007).

5. Which certifications did your company hold during 2014 and 2015? (for example none, ISO 9001, ISO 14001, etc.)

Product Innovation

6. During the two years 2014 and 2015, did your company introduce good innovations - i.e., new or significantly improved goods (exclude the simple resale of new goods and changes of a solely aesthetic nature)? Yes/No

Source: Adapted from the CIS (2012).

7. Importance of PI factors for those product innovations

\begin{tabular}{lll}
\hline Code & Item & High Medium Low Not relevant \\
\hline pi1 & Improvement of waxes formulations & \\
pi2 & Introduction or improvement of fragrances & \\
pi3 & Introduction or improvement of colors and lacquers & \\
pi4 & Environmental care & \\
pi5 & Corporate social responsibility & \\
\hline
\end{tabular}

Source: Redaction adapted from CIS (2012). The first three items represent the technical aspects and were adapted from Derudi et al. (2012), ECA (2017), NCA (2017) and Orecchio (2011). The 
last two items (pi4 and pi5) represent the envioronmental/social aspects and were adapted from Severo et al. (2015). The Spanish Innovation Panel (PITEC, 2007) also considers environmental and social aspects but as a unique question.

\section{Process Innovations}

8. During 2014 and 2015, did your enterprise introduce new or significantly improved methods of manufacturing or producing goods for...? (Check all that apply)

- None

- Molding

- Pressing / Extruding

- Drawing

- Other (please specify)
- Casting

- Deeping

- Filling

- New packing solutions

Source: Adapted from NCA (2017), ECA (2017) and CIS (2012).

9. To what degree did these innovations help the company to:

\begin{tabular}{llll}
\hline Code & Item & High Medium & Low $\begin{array}{c}\text { Not } \\
\text { relevant }\end{array}$ \\
\hline cpt1 & Control pollution & & \\
cpt2 & Have zero emissions out of the manufacturing processes & & \\
cpt3 & Reduce wastes such as energy and raw materials & & \\
\hline
\end{tabular}

Source: Adapted from CIS (2012), Kemp \& Volpi (2008), Gavronski et al. (2012) and Severo et al. (2015).

General results

10. Select the currency of your headquarters office

11. What was your company's total revenue for 2014 in your local currency? (Exclude all taxes)

12. What was your company's total revenue for 2015 in your local currency? (Exclude all taxes)

13. What was your company's average number of employees in 2014?

14. What was your company's average number of employees in 2015?

Source: Adapted from CIS (2012) 